The Journal of Animal \& Plant Sciences, 30(4): 2020, Page: 1037-1046

ISSN (print): 1018-7081; ISSN (online): 2309-8694

\title{
ENDOPHYTES AND PLANT EXTRACTS OF CARICA PAPAYA LINN. EXHIBIT PROMISING ANTIBACTERIAL AND IN-VITRO ANTITUMOR ACTIVITY
}

\author{
M. Saleem, M. T. Cheema, A. Hassan, S. Shaukat and I. Sajid* \\ Department of Microbiology and Molecular Genetics, University of the Punjab, Lahore 54590, Pakistan \\ *Corresponding author's email: imran.mmg@pu.edu.pk
}

\begin{abstract}
Microbes have always been the noteworthy source of antibiotics, enzymes and various other compounds. The emerging issue of multidrug resistance has increased the demand for mining out novel sources of antimicrobial agents. Thus, researchers are now trying to explore the underexplored microbial resources for getting new therapeutics. In this study, 42 endophytic bacteria were isolated, which includes 22 actinobacteria and 20 general bacterial strains from different parts (roots, shoots and leaves) of Carica papaya Linn. The crude extracts of endophytes and plant tissues showed remarkable antimicrobial activity against different pathogenic bacteria such as methicillin resistant Staphylococcus aureus (MRSA), E. coli and Pseudomonas aeruginosa. The extracts also exhibited notable in vitro cytotoxicity against colorectal carcinoma cell lines (HTC 116, ATTC CCL-247) by MTT assay, at the lowest concentration of $0.1 \mathrm{mg} / \mathrm{ml}$ showing growth inhibition up to $80 \%$. The plant extracts were more potent against MRSA and Bacillus, in comparison to the extracts of endophytic bacteria. Our findings suggested that endophytic bacteria and plant tissue extracts of medicinal plant Carica papaya are promising source of antimicrobial and antitumor compounds. The purification and identification of active compounds from these sources may yield some useful drug candidates.
\end{abstract}

Key words: Endophytes, Actinobacteria; Carica papaya; Plant extracts; Antimicrobial; Cytotoxicity

https://doi.org/10.36899/JAPS.2020.4.0118

Published online April 25, 2020

\section{INTRODUCTION}

The development of the drug resistance among pathogens has reduced the therapeutic options for the treatment and we can no longer rely on the existing drugs. New drugs and new sources of drugs are needed. Endophytes, the resident microbial flora of plant tissues, have occupied the central position for obtaining unique natural compounds due to their unusual habitat (Strobel and daisy 2013). In this perspective, medicinal plants could be the better source of isolation of the potentially beneficial endophytes. The treatment of infectious diseases by plants is in practice since ancient times and medicinal plants are still used in routine treatment of various ailments. Endophytic metabolites have been recognized as antimicrobials, antitumor and antiviral compounds. The symbiotic association of host plant with antimicrobial producing strains has been well documented (El-Deeb et al. 2013). This symbiotic association results in the production of more diverse and unique compounds by the microbes. Almost, all the plant species on the Earth harbour a number of various types of the endophytes within their tissues (Qin et al. 2011). Some of the new therapeutic compounds reported from the endophytic bacteria are coronamycin, munumbicins A-D (Streptomyces spp.), lupinacidins A and B (Micromonospora spp.), surfactins and fengycins (endophytic Bacillus amyloliquefaciens) (Qin et al. 2009; Sun et al. 2006). Due to the limitations of the chemotherapy, scientists are now focusing more for getting anticancer drugs from natural resources. Several species of Caricaceae family including Carica papaya exhibit anti-tumor activities by producing natural compounds present in bark, root, stem and leaf (Otsuki et al. 2010; Mello et al. 2008). The presence of broad spectrum phytochemicals make it significant as its latex has enzymes, fruits and seeds possess carotenoids, leaves contain alkaloids, phenolics present in fruit, leaves and shoots and glucosinolate also present in seeds and fruits (Milind and Gurditta 2011). Mainly Isothiocyanate, abundantly present in Papaya is responsible to eliminate cancer (Fauziya and Krishnamurthy 2013). In recent years, a number of anticancer compounds have been identified from the endophytic bacteria which make them as one of the significant source for anticancer drugs. Some of the anticancer drugs reported from endophytes are; glycopeptides, anthracyclines, anthraquinones, carzinophilin and mitomycins. Carica papaya commonly known as papaya is one of the most common plant in tropical and subtropical settings (Thomas et al. 2007). This plant attains a special position in ethnomedicines and its extracts exhibited remarkable antitumor (Otsuki et al. 2010) and antibacterial potential (Doughari et al. 2007).

In this study, we performed the comparative analysis of the extracts of endophytic microbial flora of Carica papaya Linn. for their antimicrobial potential 
against drug resistant pathogens and antitumor activity against colorectal carcinoma cell lines HCT-116.

\section{MATERIALS AND METHODS}

Sample collection: The fresh and healthy samples of roots, shoots and leaves of Carica papaya were collected from the Botanical garden of the University of the Punjab, Lahore, further processing of samples was done in the laboratory within 24 hours after collection.

Sample Treatment and Isolation: The collected fresh plant samples were washed with tap water; air dried and properly surface sterilized using already established protocol (Cao et al. 2004). After sterilization, the plant parts were dried, cut into small pieces of $0.5-1.0 \mathrm{~cm}$ and placed on the isolation media. The isolation media included: Actinomycetes Isolation Agar (g/L: Glycerol 5.0, sodium caseinate 2.0, sodium propionate 4.0, $\mathrm{K}_{2} \mathrm{HPO}_{4} \quad 0.5, \quad \mathrm{MgSO}_{4} .7 \mathrm{H}_{2} \mathrm{O} \quad 0.1$, asparagine 0.1 , $\mathrm{FeSO}_{4} .7 \mathrm{H}_{2} \mathrm{O}$ 0.001, agar 15) and Starch Casein $\mathrm{KNO}_{3}$ Agar (g/L: glycerol 10, $\mathrm{KNO}_{3} 2.0$, casein $0.3, \mathrm{NaCl} 2.0$, $\mathrm{K}_{2} \mathrm{HPO}_{4} 2.0, \mathrm{MgSO}_{4} .7 \mathrm{H}_{2} \mathrm{O} 0.05,0.02, \mathrm{FeSO}_{4} .7 \mathrm{H}_{2} \mathrm{O} 0.01$, $\mathrm{CaCO}_{3}$, agar 18) for isolating actinobacteria and Lauria Bertani Agar (g/L: trypton 10, $\mathrm{NaCl} 5.0$, yeast extract 5.0, agar 15) for the isolation of endophytic Bacillus strains. Fifty ppm (w/v) antifungal drug nystatin was added and the plates were incubated at $28^{\circ} \mathrm{C}$ for 14 days. To validate the surface sterilization, the surface sterilized plant parts were washed with sterile water and inoculated on Actinomycetes Isolation Agar without cutting into pieces (Cao et al. 2004).

Selection of presumptive endophytes: After proper incubation, endophytic bacterial colonies were selected from Actinomycetes isolation media plates with characteristic non-slimy, powdery and embedded nature. These colonies were streaked on Glucose Yeast Extract Malt Extract agar (g/L: glucose 5, malt extract 10, yeast extract 5, agar 15) for further purification and incubated at $28^{\circ} \mathrm{C}$ for 14 days to obtain purified colonies. The presumed Bacillus colonies from LB agar plates showing characteristic dry, flat, irregular and lobate margins were streaked on LB Agar plates again and incubated at $37^{\circ} \mathrm{C}$ for 24 hours for purification.

Biochemical and physiological characterization of selected endophytic bacteria: The purified endophytic bacterial strains were characterized according to the recommended biochemical tests for both groups of isolated bacterial strains. The biochemical tests for characterizing actinobacteria included test for melanin production, sugars (Sucrose, Lactose, Mannose, Galactose and Xylose) and organic acid utilizations, esculin and urea hydrolysis etc. The taxonomic characterization of the genus Bacillus included the tests such as; catalase, oxidase, starch hydrolysis, casein hydrolysis, indole production and methyl red and vogesproskauer test. For physiological analysis, properly autoclaved GYM agar plates with optimum $\mathrm{pH}$ of 8.6 were streaked with Streptomyces strain and incubated at $28^{\circ} \mathrm{C}, 37^{\circ} \mathrm{C}$ and $45^{\circ} \mathrm{C}$ for $7-14$ days. GYM agar plates were streaked with Streptomyces after adjusting $\mathrm{pH}$ of the medium at 7,9 and 11 by adding acid $(\mathrm{HCl})$ and base $(\mathrm{NaOH})$ and incubated at $28^{\circ} \mathrm{C}$ for one to two weeks (Ivanko and Varbanets 2004). GYM media was prepared by adding varying concentrations of sodium chloride (g/L; 5\%, 7\%, 9\% and 11\%). The Streptomyces strains were streaked on plates and incubated at $28^{\circ} \mathrm{C}$ for $7-14$ days.

Cultivation and extraction of the broth cultures of the endophytic bacteria and plant parts: The isolated endophytic actinobacteria were grown in GYM (Glucoseyeast-malt extract) broth for 7-10 days, while the endophytic Bacillus strains were grown in LB-broth for 48-72 hours. Plant parts (stem, fruit, leaves, bark) were dried at $37^{\circ} \mathrm{C}$ for $3-4$ days and crushed. The solvent extraction was done by adding ethyl acetate in the culture broth in equal ratio and the mixture was sonicated (Hassan and Sajid 2015). The organic layer of ethyl acetate was then separated by using separating funnel and evaporated in a rotary evaporator for obtaining dry extract. The final dried extracts were dissolved in methanol and used for the screening of antimicrobial and antitumor activity.

Screening for antimicrobial activity: The antimicrobial activity of methanolic extracts was determined against the gram positive bacterial pathogens: MRSA (Methicillin resistant Staphylococcus aureus) and gram negative pathogenic bacteria: Pseudomonas aeruginosa, Klebsiella, Proteus, and E. coli. The well diffusion method was performed for this purpose and antimicrobial potential of the isolated endophytes and plant extracts was evaluated by measuring the zone of inhibition in millimetre.

Brine Shrimp Microwell Cytotoxicity Assay: The cytotoxic properties of the methanolic extracts of endophytic bacillus, endophytic actinobacteria, and plant extracts were determined against Artemia salina larvae following the modified method reported by Solis et al. 1993.The mortality rate was calculated.

In-vitro antitumor activity by MTT assay: The antitumor activity of the crude extracts was determined by MTT [3-(4,5-dimethylthiazol-2-yl)-2,5diphenyltetrazolium bromide] colorimetric method by measuring the cell viability (Mosmann 1983). The antitumor assay was performed on human colorectal carcinoma cell lines (HTC 116. ATCC CCL-247) obtained from ATCC. The results of this assay were recorded as percentage of inhibition of the growth of the tumor cells. The optical density in each well of the 96 
well plate was determined at $540 \mathrm{~nm}$. A total of four dilutions; $10^{-1}(10 \mathrm{mg} / \mathrm{ml}), 10^{-2}(1 \mathrm{mg} / \mathrm{ml}), 10^{-3}(0.1 \mathrm{mg} / \mathrm{ml})$ and $10^{-4}(0.01 \mathrm{mg} / \mathrm{ml})$ were prepared from stocks of the extracts $(100 \mathrm{mg} / \mathrm{ml}$ in DMSO). Actinomycin D was used as positive control and DMSO blank was used as negative control. The assay was performed in triplicates and results were evaluated in the form of graphs and tables. The percentage inhibition values were calculated.

Chemical profiling of the active extracts by TLC and HPLC: The crude extracts were chemically screened through thin layer chromatography (TLC) and high performance liquid chromatography (HPLC). TLC was performed to have a finger print of the compounds present in the extracts. The TLC plates were spotted by methanolic crude extracts of actinobacteria, bacteria and plant parts separately. After that, developing solvent dichloromethane: methanol $(2: 1)$ was used to separate the compounds present in the extract. Bands were visualized under UV at $245 \mathrm{~nm}$ and $366 \mathrm{~nm}$. Anisaldehyde and Eherlich's were used as staining reagents. HPLC was performed by making 1:1 ratio of the extracts in HPLC graded methanol. The results were obtained in the form of peaks at different retention time.

Genomic DNA Isolation: Streptomyces strains were selected for high-molecular weight chromosomal DNA isolation from GYM grown cell mass. The DNA isolation was achieved by firstly harvesting cells and buffers were used to resuspend, lyse and neutralize cells. Lysate was clarified by centrifuging at $18000 \times \mathrm{g}$ for $5 \mathrm{~min}$. Washing was done with wash buffer and centrifuging $(11000 \times \mathrm{g}$, 30 seconds) and column matrix was dried by centrifuging (18000×g, 3min) followed by elution with elution buffer and centrifuging $(18000 \times \mathrm{g}, 1 \mathrm{~min})$. The eluted DNA was stored at $-20^{\circ} \mathrm{C}$.

$16 S$ rRNA Analysis: The 16S rRNA gene analysis was done through PCR amplification. The $50 \mu 1$ of the reaction mixture was prepared containing $12.5 \mu \mathrm{l}$ PCR master mix, forward (27f; 5'-AGAGTTGATCCTGGCTCAG-3') and reverse primer (1522r; 5'AAGGAGGTGATCCAGCCGCA-3') $1 \mu$ l each, template DNA $5 \mu 1$, deionized water $5.5 \mu 1$. All the 30 cycles of the PCR program were consisted of denaturation at $94^{\circ} \mathrm{C}$ for $5 \mathrm{~min}$ repeat at $94^{\circ} \mathrm{C}$ for $1 \mathrm{~min}$, annealing at $60^{\circ} \mathrm{C}$ for $1 \mathrm{~min}$ followed by extension at $72^{\circ} \mathrm{C}$ for $1 \mathrm{~min}$ and final extension at $72^{\circ} \mathrm{C}$ for $5 \mathrm{~min}$. Agarose gel electrophoresis was performed further to visualize PCR products.

Gene Sequencing and BLAST Analysis: The gel purified PCR product was sequenced on an automated sequencer using commercial facility of Macrogen, Korea. The BLAST analysis was done at National Center for Biotechnology Information (NCBI) to determine the homology of the bioactive actinobacteria and Bacillus strains with already reported strains in GenBank

\section{RESULTS}

A total of 20 endophytic Bacillus strains and 22 endophytic actinobacteria were recovered from the tissues of Carica papaya Linn. The purified strains of actinobacteria exhibited embedded, hard and dry textured colonies. The control plate incubated for the validation of surface sterilization showed no growth, which proved strains isolated to be endophytes. The strains of endophytic actinobacteria were named from $\mathrm{mA} 1$ to $\mathrm{mA} 22$ and Bacillus strains from $\mathrm{mB} 1$ to $\mathrm{mB} 20$.

Biochemical characterization included many tests. In case of melanin formation test, all strains showed positive results by changing colour of media to brownblack, except the strains $\mathrm{mA} 9$ and $\mathrm{mA} 21$. For sugar utilization as sole source of carbon, five sugars; glucose, galactose, fructose, mannitol, arabinose were used. The strains $\mathrm{mA} 4, \mathrm{~mA} 5$ and $\mathrm{mA} 7$ exhibited growth on all sugars while $\mathrm{mA} 2, \mathrm{~mA} 3, \mathrm{~mA} 13$ to $\mathrm{mA} 16$ could not use any of the sugars as carbon source. The strains $\mathrm{mA}$, mA10 and mA20 turned green media to blue for organic acid utilization. The formation of organic acid was indicated by change in media colour from purple to yellow and only the strains mA13 and mA22 were negative. Appearance of clear zones around streaked actinobacterial colonies suggested utilization of oxalate and the strains $\mathrm{mA} 2, \mathrm{~mA} 5, \mathrm{~mA} 7, \mathrm{~mA} 12$ and $\mathrm{mA} 22$ showed strongly positive results. Black colour pigmentation in esculin supplemented media indicated its hydrolysis by actinobacteria and strains mA10, mA13 and mA19 were negative (Table1).

In case of the biochemical characterization of general bacteria, firstly catalase test indicated by bubble formation after addition of bacterial culture on the drop of hydrogen peroxide and all strains were positive. The presence of cytochrome $\mathrm{C}$ oxidase enzyme in oxidase test was showed by $\mathrm{mB} 1, \mathrm{mB} 3$ to $\mathrm{mB} 11$. The strains $\mathrm{mB} 4$, $\mathrm{mB13}, \mathrm{mB14}$ and $\mathrm{mB1} 9$ showed strong positive result after adding methyl red reagent comparable with the control. Voges-proskauer was performed to examine acetone production and $\mathrm{mB} 1$ and $\mathrm{m} 2 \mathrm{~B}$ showed strong positive result indicated by the red coloured ring formation on the broth surface. The blue colour of media indicated the use of citrate as sole source of carbon and most of the strains were positive. The growth optimization experiment for temperature showed that strain $\mathrm{mA10}$ and $\mathrm{mA19}$ grew well at $37^{\circ} \mathrm{C}$, while no strain grew at $45^{\circ} \mathrm{C}$. Most of the strains showed sporulation at $\mathrm{pH} 9$ on Actinomycetes Isolation Agar. All strains exhibited rigorous growth at 5\% salt concentration in sodium chloride stress condition. Exceptional sporulation pattern was observed for strain mA10 which varied from white to reddish coloured.

The methanolic extracts exhibited promising biological activity in well diffusion assay. The methanolic extracts of strains mA12 and mA15 showed 
maximum zones of inhibition up to $32 \mathrm{~mm}$ and $34 \mathrm{~mm}$ respectively. The actinobacterial strains mA21 showed promising results against all pathogens. The strain $\mathrm{mB} 14$ gave maximum zone among endophytic bacillus strains against MRSA up to $20 \mathrm{~mm}$ (Table 2). Among plant parts, fruit and bark exhibited maximum zones of inhibition up to $26 \mathrm{~mm}$ against Bacillus and MRSA respectively (Table $3)$. The extracts of all plant parts showed good activity against MRSA (Figure 1).

The high toxicity percentage of $55 \%$ was shown by $\mathrm{mA} 4$ and $\mathrm{mA} 8$, followed by $40 \%$ shown by $\mathrm{mA} 12$. The minimum percentage of $6.66 \%$ was shown by $\mathrm{mA} 2$ and mA10 against Artemia salina larvae.

In case of in vitro anti-tumor activity, four dilutions $10^{-1}, 10^{-2}, 10^{-3}, 10^{-4}$ in triplicates was used. The mortality above $60 \%$ in second and third dilution was considered significant. The strains $\mathrm{mA} 4, \mathrm{~mA} 11, \mathrm{mB} 1$, $\mathrm{mB} 2$, and $\mathrm{mB} 6$ showed percentage inhibition of colorectal carcinoma cells up to $80 \%$ (Table 4). The plant extracts of fruit and leaves also showed remarkable activity, above $80 \%$ growth inhibition of tumor cells (Table 5).

The chemical screening by thin layer chromatography and high performance liquid chromatography exhibited impressive diversity of the active components. The methanolic crude extracts were spotted and after staining with Anisaldehyde, endophytic actinobacteria showed purple and pink bands. Brown band was shown by each sample. Orange bands were exhibited by the extracts of strains mA1, mA8 and mA19 after Ehrlich's reagent spray and yellow bands by $\mathrm{mA} 3$, mA4 and mA10. The plant extracts of stem, leaves, bark and fruit exhibited unique red coloured compounds. HPLC-UV analysis was also done and comparison of standard ultraviolet absorption of secondary metabolites at different retention times was done. Strain mA8 showed two maximum peaks at 2.39 and 2.56 respectively (Figure 2). Likewise, strain mA19 showed two large peaks at 2.36 and 2.43. Strain mA22 showed maximum peak at 2.58 .

The genomic DNA was amplified by polymerase chain reaction and after BLAST analysis noteworthy strain was submitted to the Genbank and accession number was allotted to the strains. The selected 5 strains were matched with already discovered strains (Table 6).
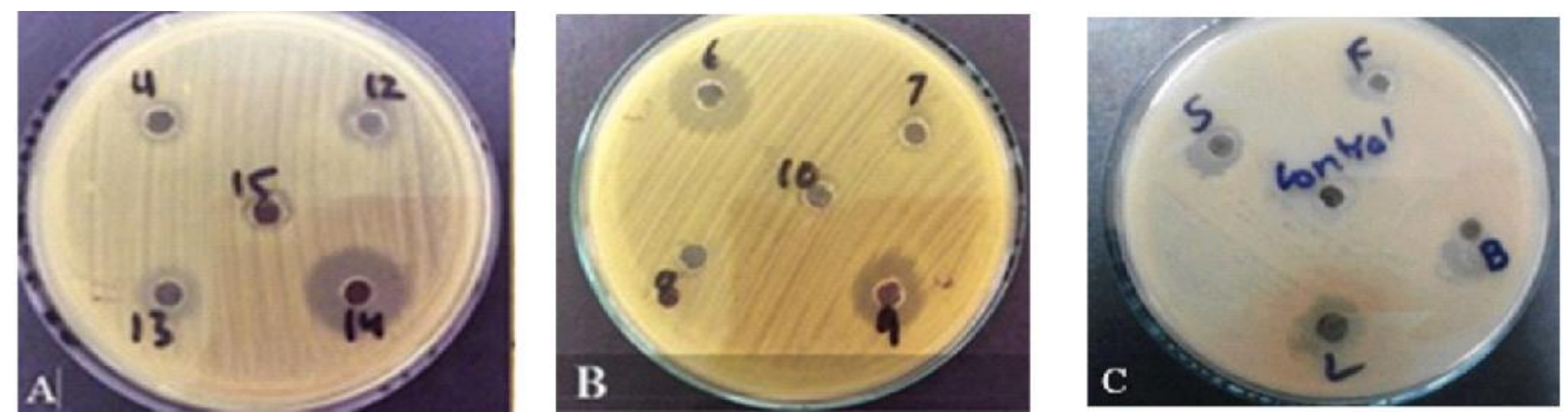

Fig. 1 Antibacterial Assay: (A) Strain m14A showing maximum zone of inhibition against MRSA (B) The strain m6A and m9A showing significant zones of inhibition against Pseudomonas (C) Methanolic extracts of plant parts showing zones of inhibition against E.coli

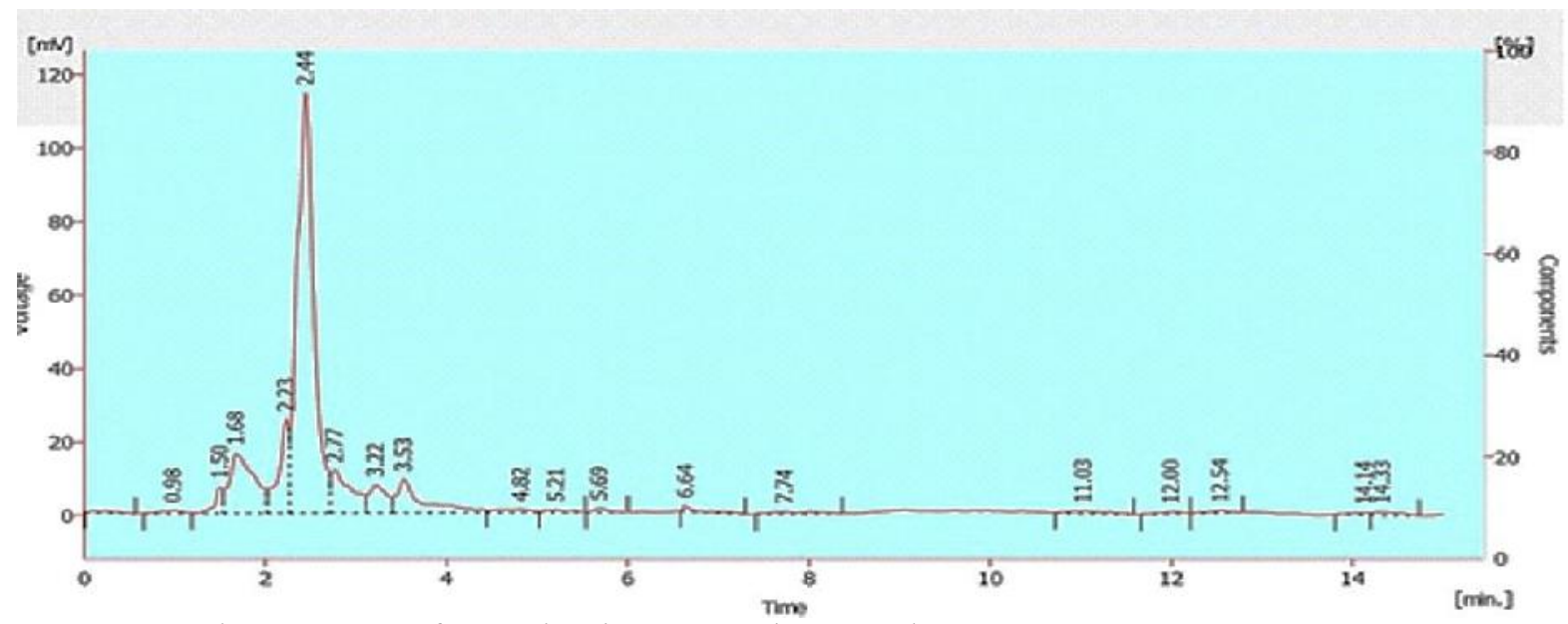

Fig. 2 HPLC-UV chromatogram of m8A showing one maximum peak 


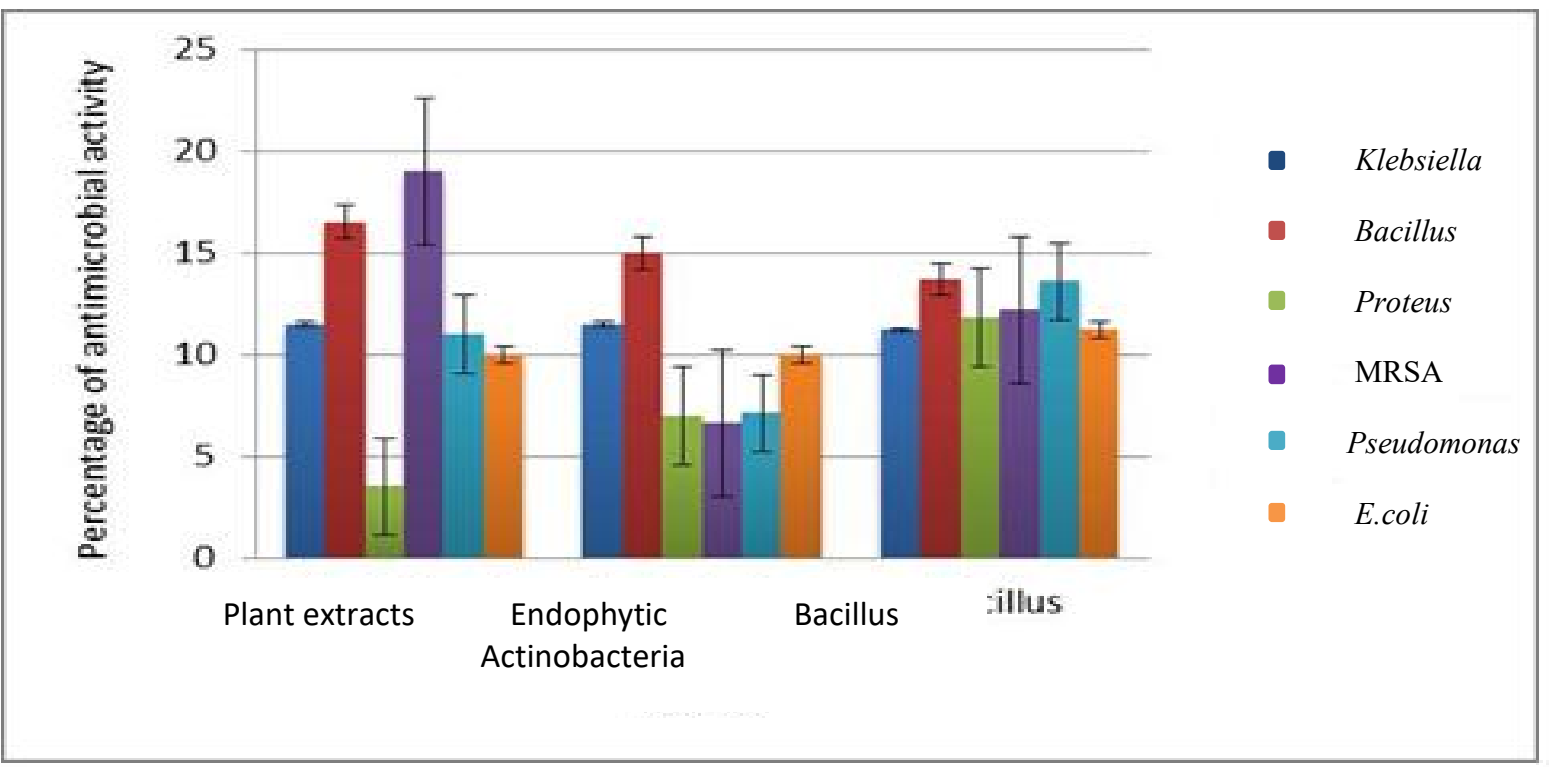

Fig. 3 Comparative analysis of antimicrobial activity of endophytic actinobacteria and plant extracts of Carica papaya against multidrug resistant pathogens, plant extracts being more active against MRSA, endophytic Bacillus strains showing compatible activity against all pathogens while endophytic actinobacteria are more promising against Bacillus

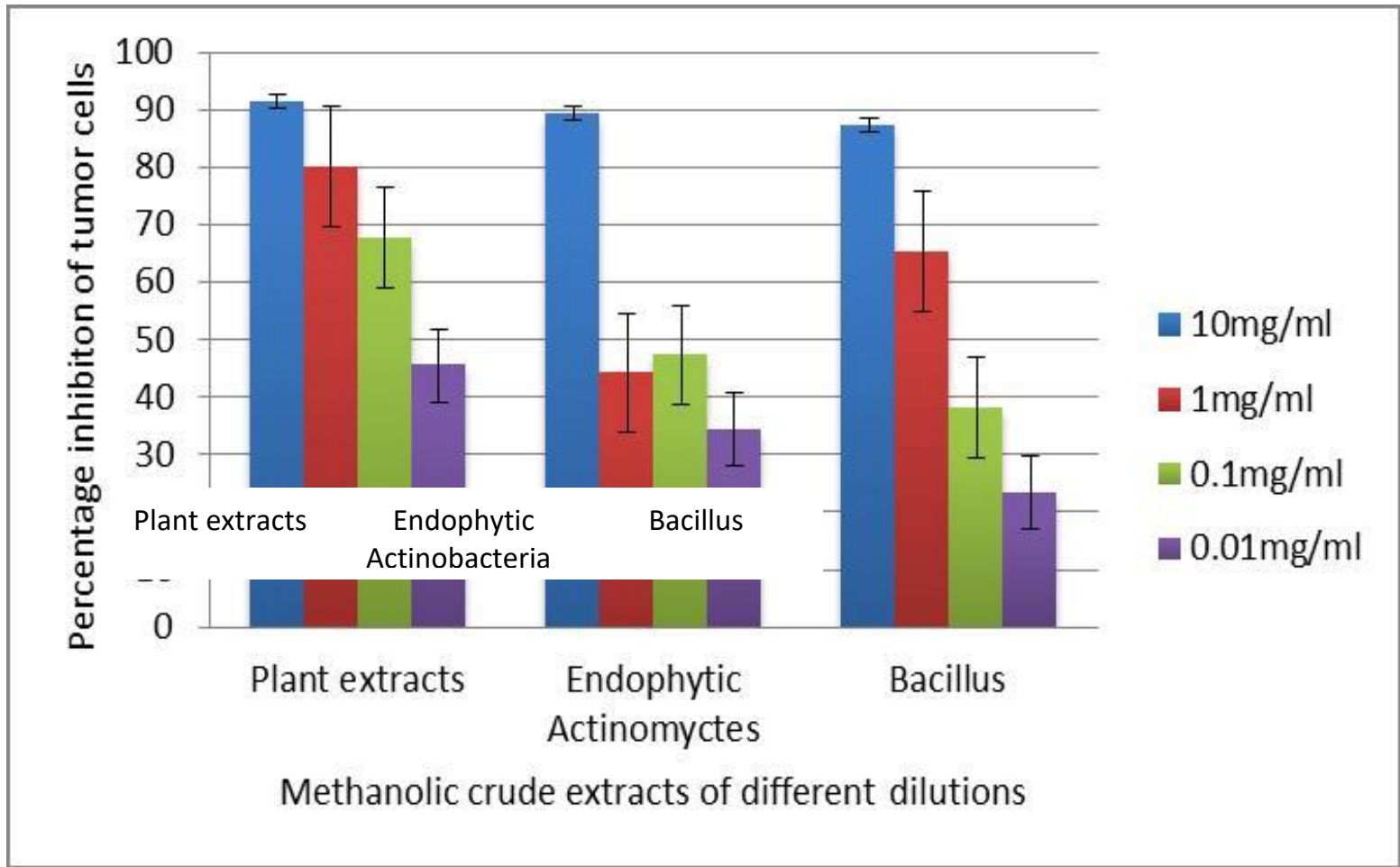

Fig. 4 Comparative analysis of antitumor activity of endophytic actinobacteria and plant extracts of Carica papaya against colorectal carcinoma cell line HCT 116, plant extracts being most active at even lowest concentration followed by endophytic actinobacteria and Bacillus strains 
Table 1. Biochemical characteristics of selected endophytic actinobacteria.

\begin{tabular}{|c|c|c|c|c|c|c|c|c|c|c|c|}
\hline \multirow{2}{*}{$\begin{array}{l}\text { Sr. } \\
\text { No }\end{array}$} & \multirow{2}{*}{$\begin{array}{c}\text { Isolated } \\
\text { Strains }\end{array}$} & \multirow{2}{*}{$\begin{array}{l}\text { Melanin } \\
\text { Formation }\end{array}$} & \multirow{2}{*}{$\begin{array}{c}\text { Utilization } \\
\text { of organic } \\
\text { acid }\end{array}$} & \multirow{2}{*}{$\begin{array}{l}\text { Utilization } \\
\text { of oxalate }\end{array}$} & \multirow{2}{*}{$\begin{array}{c}\text { Formation } \\
\text { of organic } \\
\text { acid }\end{array}$} & \multirow{2}{*}{$\begin{array}{c}\text { Esculin } \\
\text { hydrolysis }\end{array}$} & \multicolumn{5}{|c|}{$\begin{array}{c}\text { Sugar utilization test as } \\
\text { carbon source }\end{array}$} \\
\hline & & & & & & & G & $\mathrm{M}$ & A & Gl & $\mathrm{F}$ \\
\hline 1 & mA1 & $\ldots$ & .. & - & .. & .. & - & . & - & . & . \\
\hline 2 & mA2 & $\ldots$ & .. & - & $\ldots$ & $\ldots$ & - & - & - & . & . \\
\hline 3 & $\mathbf{m A 3}$ & .. & . & . & .. & . & - & - & - & . & - \\
\hline 4 & mA4 & $\ldots$ & .. & - & .. & .. & . & . & . & . & . \\
\hline 5 & mA5 & $\ldots$ & .. & - & .• & $\ldots$ & . & . & . & . & . \\
\hline 6 & mA6 & $\ldots$ & .. & - & .. & .. & . & - & . & . & . \\
\hline 7 & mA7 & $\ldots$ & $\ldots$ & - & $\ldots$ & $\ldots$ & . & . & . & . & . \\
\hline 8 & mA8 & .. & .. & - & . & - & . & . & . & . & . \\
\hline 9 & mA9 & $\ldots$ & . & .. & .. & - & - & - & - & . & . \\
\hline 10 & mA10 & $\ldots$ & $\ldots$ & .. & $\ldots$ & - & . & . & - & . & . \\
\hline 11 & mA11 &.. &.. & .. &.. & .. & - & . & . & . & . \\
\hline 12 & mA12 & $\ldots$ & .. & - & .. & $\ldots$ & - & - & - & . & . \\
\hline 13 & mA13 & $\ldots$ & . & .. & - & - & - & - & - & . & . \\
\hline 14 & mA14 & $\ldots$ & .. & .. & .. & .. & - & . & . & . & . \\
\hline 15 & mA15 & $\ldots$ & . & - & - & - & - & . & . & . & . \\
\hline 16 & mA16 & $\ldots$ & .. & - & .. & .. & . & . & . & . & . \\
\hline 17 & mA17 & - & .. & - & .. & .. & . & - & . & . & . \\
\hline 18 & mA18 & $\ldots$ & .. & . & .. & . & . & - & . & . & - \\
\hline 19 & mA19 & $\ldots$ & .. & - & .. & - & - & . & . & . & - \\
\hline 20 & mA20 & $\ldots$ & $\ldots$ & - & $\ldots$ & .. & - & . & • & . & . \\
\hline 21 & mA21 & - &.. & - & .. & .. & - & . & . & . & . \\
\hline 22 & mA22 & $\ldots$ & . & - & - & $\ldots$ & . & . & . & . & - \\
\hline
\end{tabular}

Interpretation: strong positive ..., positive .., negative -

Sugar Utilization Test: $\mathrm{G}=$ Galactose, $\mathrm{M}=$ Mannitol, $\mathrm{A}=$ Arabinose, $\mathrm{Gl}=\mathrm{Glucose}, \mathrm{F}=$ Fructose

Table 2: Antimicrobial activity of endophytic actinobacteria and general bacteria against multi-drug resistant pathogens.

\begin{tabular}{|c|c|c|c|c|c|c|c|c|c|c|c|c|c|c|}
\hline \multirow{2}{*}{$\begin{array}{l}\text { Sr. } \\
\text { No. }\end{array}$} & \multirow{2}{*}{ Strain } & \multicolumn{6}{|c|}{ Zone of inhibition (millimetre) } & \multirow{2}{*}{ Strain } & \multicolumn{6}{|c|}{ Zone of inhibition (millimetre) } \\
\hline & & $\mathbf{K}$ & B & $\mathbf{P}$ & $\mathbf{M}$ & Ps & $\mathbf{E}$ & & $\mathbf{K}$ & B & $\mathbf{P}$ & $\mathbf{M}$ & Ps & $\mathbf{E}$ \\
\hline 1 & mA1 & 12 & 26 & 14 & - & 08 & 18 & mB1 & - & 12 & 14 & 12 & 14 & 12 \\
\hline 2 & mA2 & 18 & 22 & - & - & 08 & 12 & mB2 & 10 & 10 & 10 & 12 & - & 10 \\
\hline 3 & mA3 & 14 & 16 & - & - & 10 & 10 & mB3 & - & 14 & 10 & - & 18 & 10 \\
\hline 4 & mA4 & 14 & - & - & - & 10 & 10 & mB4 & - & 12 & 10 & 08 & - & 08 \\
\hline 5 & mA5 & 16 & 16 & 16 & 14 & 08 & 10 & mB5 & 12 & 12 & 10 & 14 & 10 & - \\
\hline 6 & mA6 & 12 & - & - & - & 08 & 08 & mB6 & - & 08 & 18 & 18 & 18 & - \\
\hline 7 & $\mathbf{m A} 7$ & - & - & 10 & 14 & 10 & - & mB7 & - & 14 & 10 & 12 & - & 12 \\
\hline 8 & mA8 & 08 & - & - & 10 & 12 & 08 & mB8 & 10 & 14 & 08 & 30 & 08 & - \\
\hline 9 & mA9 & - & 18 & - & 10 & 08 & 10 & mB9 & - & 14 & 18 & 18 & 18 & 16 \\
\hline 10 & mA10 & 08 & 20 & 12 & - & 16 & 12 & mB10 & - & 08 & 08 & 14 & 12 & - \\
\hline 11 & mA11 & 08 & 18 & 08 & - & 08 & 10 & mB11 & 08 & 14 & - & 08 & - & 17 \\
\hline 12 & mA12 & 32 & 20 & 12 & - & 16 & 10 & mB12 & 08 & 26 & 16 & 14 & 16 & - \\
\hline 13 & mA13 & 14 & 22 & - & - & 08 & 10 & mB13 & 08 & 18 & - & 12 & 08 & - \\
\hline 14 & mA14 & - & 14 & 18 & - & - & 10 & mB14 & 08 & 16 & 12 & 20 & 10 & 13 \\
\hline 15 & mA15 & 34 & 10 & 18 & - & 08 & 08 & mB15 & 08 & 12 & 12 & 10 & 10 & - \\
\hline 16 & mA16 & 12 & 14 & 14 & 08 & - & 08 & mB16 & 16 & - & 14 & 12 & 08 & 12 \\
\hline 17 & mA17 & 12 & 12 & - & 18 & - & 10 & mB17 & - & - & 08 & - & 08 & 08 \\
\hline 18 & mA18 & 10 & 10 & - & 10 & - & 08 & mB18 & 22 & - & 12 & 08 & 14 & 05 \\
\hline 19 & mA19 & - & 12 & - & 12 & - & 08 & mB19 & - & - & - & - & - & - \\
\hline 20 & $\mathbf{m A 2 0}$ & 10 & 12 & 10 & 16 & - & 08 & mB20 & 14 & 16 & 12 & 10 & - & 12 \\
\hline 21 & mA21 & 10 & 16 & 14 & 16 & 10 & 18 & & & & & & & \\
\hline 22 & mA22 & 10 & 18 & 10 & 18 & 10 & 14 & & & & & & & \\
\hline
\end{tabular}


Table 3. Antimicrobial activity of methanolic extracts of plant parts of Carica papaya Linn. against multi-drug resistant pathogens.

\begin{tabular}{|c|c|c|c|c|c|c|c|}
\hline \multirow{2}{*}{$\begin{array}{l}\text { Sr. } \\
\text { No. }\end{array}$} & \multirow[t]{2}{*}{ Plant parts } & \multicolumn{6}{|c|}{ Zone of inhibition (millimetre) } \\
\hline & & Klebsiella & Bacillus & Proteus & MRSA & Pseudomonas & E.coli \\
\hline 1 & Stem & - & 12 & - & 18 & 14 & 10 \\
\hline 2 & Fruit & 14 & 26 & - & 16 & 10 & 12 \\
\hline 3 & Leaves & 14 & 18 & - & 16 & 10 & 10 \\
\hline 4 & Bark & 18 & 10 & 14 & 26 & 10 & 8 \\
\hline
\end{tabular}

Table 4. In vitro anti-tumor activity of crude extracts of endophytic actinobacteria and Bacillus endophytic strains against colorectal carcinoma cell lines (HTC 116.ATCC CCL-247) at varying dilutions.

\begin{tabular}{|c|c|c|c|c|c|c|c|c|c|c|}
\hline \multirow{2}{*}{$\begin{array}{l}\text { Sr. } \\
\text { No. }\end{array}$} & \multirow[t]{2}{*}{ Extracts } & \multicolumn{4}{|c|}{ Percentage inhibition } & \multirow[t]{2}{*}{ Extracts } & \multicolumn{4}{|c|}{ Percentage inhibition } \\
\hline & & $10^{-1}$ & $10^{-2}$ & $10^{-3}$ & $10^{-4}$ & & $10^{-1}$ & $10^{-2}$ & $10^{-3}$ & $10^{-4}$ \\
\hline 1 & mA1 & 94 & 66 & 72 & 50 & mB1 & 91 & 81 & 55 & 27 \\
\hline 2 & $\mathbf{m A 2}$ & 94 & 72 & 66 & 50 & mB2 & 91 & 82 & 36 & 00 \\
\hline 3 & mA3 & 88 & 38 & 66 & 44 & mB3 & 91 & 64 & 18 & 18 \\
\hline 4 & mA4 & 94 & 83 & 50 & 22 & mB4 & 91 & 73 & 36 & 00 \\
\hline 5 & mA5 & 94 & 61 & 77 & 66 & mB5 & 91 & 91 & 67 & 55 \\
\hline 6 & mA6 & 88 & 50 & 33 & 27 & mB6 & 91 & 82 & 73 & 45 \\
\hline 7 & $\mathbf{m A} 7$ & 94 & 61 & 72 & 72 & mB7 & 91 & 73 & 36 & 09 \\
\hline 8 & mA8 & 92 & 30 & 62 & 46 & mB8 & 86 & 71 & 57 & 57 \\
\hline 9 & mA9 & 92 & 15 & 07 & 00 & mB9 & 86 & 71 & 43 & 00 \\
\hline 10 & mA10 & 92 & 00 & 61 & 00 & mB10 & 71 & 57 & 00 & 00 \\
\hline 11 & mA11 & 92 & 38 & 84 & 30 & mB11 & 71 & 57 & 00 & 00 \\
\hline 12 & mA12 & 92 & 61 & 76 & 30 & mB12 & 71 & 57 & 29 & 00 \\
\hline 13 & mA13 & 84 & 53 & 15 & 00 & mB13 & 86 & 57 & 57 & 57 \\
\hline 14 & mA14 & 92 & 69 & 69 & 69 & mB14 & 86 & 43 & 43 & 43 \\
\hline 15 & mA15 & 81 & 72 & 45 & 72 & mB15 & 92 & 50 & 28 & 14 \\
\hline 16 & mA16 & 90 & 00 & 63 & 00 & mB16 & 92 & 78 & 50 & 43 \\
\hline 17 & mA17 & 63 & 00 & 00 & 00 & mB17 & 92 & 35 & 14 & 28 \\
\hline 18 & mA18 & 90 & 18 & 00 & 45 & mB18 & 92 & 42 & 36 & 07 \\
\hline 19 & mA19 & 90 & 45 & 27 & 36 & mB19 & 92 & 78 & 43 & 21 \\
\hline 20 & mA20 & 90 & 27 & 09 & 09 & mB20 & 92 & 64 & 43 & 43 \\
\hline 21 & mA21 & 90 & 72 & 45 & 45 & & & & & \\
\hline 22 & mA22 & 92 & 43 & 43 & 43 & & & & & \\
\hline
\end{tabular}

Table 5. In vitro anti-tumor activity of plant extracts against colorectal carcinoma cell line (HTC 116.ATCC CCL247) at varying dilutions.

\begin{tabular}{|c|c|c|c|c|c|}
\hline \multirow[t]{2}{*}{ Sr. no. } & \multirow[t]{2}{*}{ Plant extracts } & \multicolumn{4}{|c|}{ Percentage inhibition } \\
\hline & & $10^{-1}$ & $10^{-2}$ & $10^{-3}$ & $10^{-4}$ \\
\hline 1 & Stem & 92 & 72 & 47 & 37 \\
\hline 2 & Fruit & 92 & 82 & 75 & 54 \\
\hline 3 & Leaves & 90 & 89 & 80 & 65 \\
\hline 4 & Bark & 92 & 78 & 69 & 26 \\
\hline
\end{tabular}

Dilutions: $10^{-1}=10 \mathrm{mg} / \mathrm{ml}, 10^{-2}=1 \mathrm{mg} / \mathrm{ml}, 10^{-3}=0.1 \mathrm{mg} / \mathrm{ml}, 10^{-4}=0.01 \mathrm{mg} / \mathrm{ml}$

Table 6. Similarity index of the selected strains with already discovered strains.

\begin{tabular}{ccccc}
\hline Sr. No. & Selected strains & Accession numbers & Similarity (\%) & Similarity with \\
\hline 1 & $\mathrm{~m} 3 \mathrm{~B}$ & MG429060 & 100 & Bacillus subtilis strain LLP-2 \\
2 & $\mathrm{~m} 5 \mathrm{~B}$ & MG429061 & 100 & Bacillus subtilis strain ACGF2-1 \\
3 & $\mathrm{~m} 8 \mathrm{~B}$ & MG429062 & 100 & Bacillus toyonensis \\
4 & $\mathrm{~m} 18 \mathrm{~B}$ & MG429063 & 100 & Bacillus subtilis subsp. spizizenii \\
5 & $\mathrm{~m} 20 \mathrm{~B}$ & MG429064 & 100 & Bacillus pumilus \\
\hline
\end{tabular}




\section{DISCUSSION}

Endophytic actinobacteria, residing the inner tissues of living plants, have fascinated scientists. The rise of multidrug resistance in pathogens and damaging after effects of many antibiotics has promoted concern to hunt for novel antimicrobials particularly from plant origin. The limited literature accessible confirmed that Carica papaya comprise bioactive phytochemicals in abundance which helps in combating cancer, further scientific research is needed to comprehend the procedure.

In this study, 20 endophytic bacteria and 22 endophytic actinobacteria were isolated from Carica papaya Linn. after proper surface sterilization of various plant parts. Burgdorf et al. (2014) and Cui et al. (2011) did surface sterilization with same process. The efficiency checking of the procedure has already been done by Kumar et al. (2016) by incubating agar plate with uncut plant part. Thus, we obtained true endophytes after removing all epiphytes successfully showing effectiveness of procedure. Most of the endophytic strains were recovered from roots of the plants in comparison to other parts. Our results are similar to the findings of Zakaria et al. (2016), Verma et al. (2009) and Cao et al. (2005) who isolated maximum number of endophytes from roots.

Morphological, physiological and biochemical characteristics of the isolated strains were determined by conventional approaches described in Bergey's manual of determinative bacteriology (Bergey et al. 1934) and Nonomura's identification key (Nonomura 1974) and results showed that purified endophytic actinobacterial isolates belong to the genus Streptomyces (Goodfellow et al. 1986) while endophytic general bacteria belong to the genus Bacillus. To perform physiological characterization the growth conditions were optimized for endophytic actinobacteria. Endophytic actinobacteria grew better at $28^{\circ} \mathrm{C}$ followed by $37^{\circ} \mathrm{C}$ indicating their mesophilic character. The optimum $\mathrm{pH}$ was 9.0 followed by 7.0 showing them to be alkalophilic. Most of the isolates declared halotolerant because they grew well at high salt $(\mathrm{NaCl})$ concentration i.e. $5 \mathrm{~g} / 100 \mathrm{ml}$ and $7 \mathrm{~g} / 100 \mathrm{ml}$.

The biological screening of crude extracts was done by well diffusion method. These results proposed that strains are a good source of remarkable antibacterial compounds. Table 3 shows that strains were equally effective against gram positive pathogenic bacteria (Bacillus and methicillin resistant Staphylococcus aureus) and gram negative pathogenic bacteria (E.coli, Proteus, Pseudomonas and Klebsiella). But unusual behaviour of some strains was also observed because of difference in their cell wall composition, as also observed by Scherrer and Gerhardt (1971). The concentration of some media components also effects antibiotic production in fermentation media (Sanchez and Demain
2002; Parekh et al. 2000). With reference to the general bacterial strains, the finest results were noted against MRSA and Proteus. If we try to find the effects of all plant parts of Carica papaya, they exhibited supreme activities against MRSA. The higher activities of methanolic extracts of Carica papaya plant parts were stated by Doughari et al. (2007) against Gram negative bacteria, while in current study, maximum zone was detected against Gram positive bacteria (Bacillus) which is a noteworthy finding that Carica papaya plant has the potential to produce broad spectrum antibiotics. In comparative studies, endophytic Bacillus strains exhibited promising activity against all test strains but overall plant extracts showed maximum activities against Bacillus and MRSA (Figure 3). Thus, plant parts of Carica papaya are promising in combating infections as it is easily available around the globe and without any doubt is an economical remedy.

The cytotoxicity test was done to assess the extract's ability to produce toxic compounds. The experiment showed higher percentage mortality (55\%) followed by percentage mortality of $40 \%$ by mA 12 and mB14 which also showed remarkable antimicrobial activity, while some other strains showed minimum percentage inhibition (6.66\%) in comparison with blind sample $(0 \%)$. These results indicated that extracts of Bacillus and actinobacterial strains have low to moderate cytotoxicity and can be good antimicrobials.

In-vitro anti-tumor activity was determined by MTT assay performed on colorectal carcinoma cell line HCT-116, ATCC CCL-247. Cell proliferation and viability was measured in vitro to check a cell population's reaction to external factors. Extracts of plant parts exhibited maximum inhibition of the cells above $80 \%$. Our results showed that endophytes and plant parts of Carica papaya can significantly produce antitumor compounds which after further scale up production (fermentation), purification and identification could be developed as potential drug candidates (Figure 4). Antitumor compounds from endophytic actinobacteria and Bacillus has been reported by Taechowisan et al. (2007) who screened an antitumor compound; 4arylcoumarins from the endophytic Streptomyces aerufaciens. Similarly, Chen et al. (2013) isolated endophytic Bacillus amyloliquifaciens whose extracted exoploysaccharides exhibited remarkable antitumor activity against gastric cancer. Many studies have reported the aqueous extracts of leaves of Carica papaya as potential source of bioactive compounds but a little has been done with other parts such as bark, fruit and stem.

The chemical profiling of extracts was performed through TLC and after staining it exhibited the occurrence of amines, sugars and indole like compounds. Staining with Anisaldehyde showed red bands, indicated the presence of esters. Purple spots were indicative of amines and phenols. Green and yellow spots indicated the 
presence of methylpentoses. After staining with Ehrilch's reagent, yellow and purple coloured bands indicated the presence of indoles and amines. This screening provided the evidence that each isolate showed different pattern by producing different types of metabolites, independent of their biochemical and morphological characteristics. HPLC-UV was also conducted with the purpose of separation, identification and quantification of compounds present in the extracts. The maximum peaks at retention times 2.34 and 2.39 minutes were showed by strain $\mathrm{mA} 2$, indicated that two major compounds were present. Similarly mA17 gave 6 maximum peaks. The chromatogram of stem extract showed 4 major peaks, so we can infer that it would have four major compounds.

Nucleic acid investigation is the most likely methodology to classification. The evolutionary relationships are usually investigated by sequence analysis of ribosomal RNA within different genera of bacteria and the sequence analysis of $16 \mathrm{~S}$ rRNA is the most significant taxonomic tool used to determine phylogenetic relationship and define the generic groups of actinobacteria. Some strains exhibited super activity and produced noteworthy metabolites which were identified up to specie level.

Conclusion: As the discovery of novel compounds is declining in drug market and resistance against drugs has been developed by pathogens, it is essential now to find new compounds which have the ability to fight against lethal pathogens. So it is not less than a wonder to have plant extracts with good antitumor and antimicrobial potential in such situation, where the herbal medicine is economical to use, and have least side effects and easily available to maximum population. To the best of our knowledge, this is the first report evaluating the comparative antimicrobial and antitumor potential of endophytic bacteria of papaya plant with antimicrobial and antitumor activity of its plant extracts. Further scale up production of the bioactive compounds from these endophytic bacteria and identification of compounds by the spectroscopic techniques including NMR and mass spectrometry might yield commercially useful drugs.

Acknowledgements: This work was supported by the research grant (HEC-NRPU Project 2121) from Higher Education Commission Pakistan, which is duly acknowledged.

\section{REFERENCES}

Bergey, D.H. (1934). Bergey's manual of determinative bacteriology. The Williams and WilkinsCo; Baltimore (USA). $664 \mathrm{p}$

Burgdorf, R.J., M.D. Laing, C.D. Morris, and S.F. JamalAlly (2014). A procedure to evaluate the efficiency of surface sterilization methods in culture-independent fungal endophyte studies. Braz. J. Microbiol. 45(3): 977-983.

Cao, L., Z. Qiu, X. Dai, H. Tan, Y. Lin, and S. Zhou (2004). Isolation of endophytic actinomycetes from roots and leaves of banana (Musa acuminata) plants and their activities against Fusarium oxysporumf. sp. cubense. World. J. Microbiol. Biotechnol. 20(5): 501-504.

Cao, L., Z. Qiu, J. You, H. Tan, and S. Zhou (2005). Isolation and characterization of endophytic streptomycete antagonists of Fusarium wilt pathogen from surface-sterilized banana roots. FEMS Microbiol. Let. 247(2): 147-152.

Chen, Y.T., Q. Yuan, L.T. Shan, M.A. Lin, D.Q. Cheng, and C.Y. Li (2013). Antitumor activity of bacterial exopolysaccharides from the endophyte Bacillus amyloliquefaciens sp. isolated from Ophiopogon japonicus. Oncol. Let. 5(6): 1787 1792.

Cui, J.L., S.X. Guo, and P.G. Xiao (2011). Antitumor and antimicrobial activities of endophytic fungi from medicinal parts of Aquilaria sinensis. J. Zhejiang. Univ. Sci. B. 12(5): 385-392.

Doughari, J., A. Elmahmood, and S. Manzara (2007). Studies on the antibacterial activity of root extracts of Carica papaya L. African. J. Microbiol. Res. 1(3): 037-041.

El-Deeb, B., K. Fayez, and Y. Gherbawy (2013). Isolation and characterization of endophytic bacteria from Plectranthus tenuiflorus medicinal plant in Saudi Arabia desert and their antimicrobial activities. J. plant interact. 8(1): 56-64.

Fauziya, S., and R. Krishnamurthy (2013). Papaya (Carica papaya): source material for anticancer. CIBTech J. Pharm. Sci. 2(1): 25-34.

Goodfellow, M., S.T. Williams, and G. Alderson (1986). Transfer of Kitasatoa purpurea Matsumae and Hata to the Genus Streptomyces as Streptomyces purpureus comb. nov. Syst. App. Microbiol. 8(1-2): 65-66.

Hassan, A., and I. Sajid (2015). Inhibitory Effects of Plant Extracts and Putative Endophytic Actinomycetes from the Selected Members of Meliaceae Family against MDR Pseudomonas aeruginosa. Eur. J. Med. plant. 10(4): 1-14

Ivanko, O.V., and L.D. Varbanets (2004). Keratinolytic activity of Streptomyces sp. 1382. Mikrobiolohichnyi zhurnal (Kiev, Ukraine: 1993). 66(1): 3-9

Kumar, A., R. Singh, A. Yadav, D.D. Giri, P.K. Singh, and K.D. Pandey (2016). Isolation and characterization of bacterial endophytes of Curcuma longa L. 3 Biotech. 6(1): 60

Milind, P., and G. Gurditta (2011). Basketful benefits of Papaya. Int. res. J. pharm. 2(7): 6-12. 
Mello, V.J., M.T.R. Gomes, F.O. Lemos, J.L. Delfino, S.P. Andrade, M.T. Lopes, and C.E. Salas (2008). The gastric ulcer protective and healing role of cysteine proteinases from Carica candamarcensis. Phytomed. 15(4): 237-244.

Mosmann, T. (1983). Rapid colorimetric assay for cellular growth and survival: application to proliferation and cytotoxicity assays. J. Immunol. Meth. 65(1-2): 55-63.

Nonomura, H. (1974). Key for classification and identification of 458 species of the Streptomycetes included in ISP. J. Ferment. Technol. 52: 78-92

Otsuki, N., N.H. Dang, E. Kumagai, A. Kondo, S. Iwata, and C. Morimoto (2010). Aqueous extract of Carica papaya leaves exhibits anti-tumor activity and immunomodulatory effects. J. Ethnopharmacol. 127(3): 760-767.

Parekh, S., V.A. Vinci, and R.J. Strobel (2000). Improvement of microbial strains and fermentation processes. Appl. Microbiol. Biotechnol. 54(3): 287-301.

Qin, S., J. Li, H.H. Chen, G.Z. Zhao, W.Y. Zhu, C.L. Jiang, L.H. Xu, and W.J. Li (2009). Isolation, diversity, and antimicrobial activity of rare actinobacteria from medicinal plants of tropical rain forests in Xishuangbanna, China. Appl. Environ. Microbiol. 75(19): 6176-6186.

Qin, S., Xing, K., J.H. Jiang, L.H. Xu, and W.J. Li (2011). Biodiversity, bioactive natural products and biotechnological potential of plantassociated endophytic actinobacteria. Appl. Microbiol. Biotechnol. 89(3): 457-473.

Sanchez, S., and A.L. Demain (2002). Metabolic regulation of fermentation processes. Enzy. Microb. Technol. 31(7): 895-906.
Scherrer, R., and P. Gerhardt (1971). Molecular sieving by the Bacillus megaterium cell wall and protoplast. J. Bacteriol. 107(3): 718-735.

Solis, P.N., C.W. Wright, M.M. Anderson, M.P. Gupta, and J.D. Phillipson (1993). A microwell cytotoxicity assay using Artemia salina (brine shrimp). Plant. med. 59(03): 250-252.

Strobel, G., and B. Daisy (2003). Bioprospecting for microbial endophytes and their natural products. Microbiol. Mol. Boil. Rev. 67(4): 491-502.

Sun, L., Z. Lu, X. Bie, F. Lu, and S. Yang (2006). Isolation and characterization of a co-producer of fengycins and surfactins, endophytic Bacillus amyloliquefaciens ES-2, from Scutellaria baicalensis Georgi. World. J. Microbiol. Biotechnol. 22(12): 1259-1266.

Taechowisan, T., C. Lu, Y. Shen, and S. Lumyong (2007). Antitumor activity of 4-arylcoumarins from endophytic Streptomyces aureofaciens CMUAc130. J. cancer Res. Therap. 3(2): 86.

Thomas, P., S. Kumari, G.K. Swarna, and T. Gowda (2007). Papaya shoot tip associated endophytic bacteria isolated from in vitro cultures and hostendophyte interaction in vitro and in vivo. Can. J. Microbiol. 53(3): 380-390.

Verma, V.C., S.K. Gond, A. Kumar, A. Mishra, R.N. Kharwar, and A.C. Gange (2009). Endophytic actinomycetes from Azadirachta indica A. Juss.: isolation, diversity, and anti-microbial activity. Microb. Ecol. 57(4): 749-756.

Zakaria, L., M.I.M. Jamil, and I.S.M. Anuar (2016). Molecular Characterisation of Endophytic Fungi from Roots of Wild Banana (Musa acuminata). Trop. life sci. res. 27(1): 153. 